\title{
PRODUKCJA PARTNERSKA W INTERNECIE JAKO PRZYKŁAD GLOBALNEJ DEZINTEGRACJI PROCESU PRODUKCJ
}

\section{WSTĘP}

Produkcja jest świadomą i celową działalnością człowieka przekształcającą zasoby oraz siły przyrody w dobra ekonomiczne ${ }^{1}$. W ekonomii neoklasycznej przyjmuje się, że ma ona charakter procesu, w ramach którego czynniki produkcji przeobraża się $\mathrm{w}$ produkty. Proces produkcji rozumie się jako rodzaj funkcji, określającej odpowiednią kombinację stosowanych zasobów, która pozwala na osiągnięcie optymalnej wydajności ${ }^{2}$. Organizacyjnym wyrazem funkcji produkcji jest ustrukturyzowane przedsiębiorstwo, gdyż „...efektywność wymaga zwykle produkcji na wielką skalę, zgromadzenia znacznych zasobów finansowych oraz starannego zarządzania, a także monitorowania codziennych działań”3.

Proces produkcji wymaga więc integracji szeregu podstawowych czynników produkcji (kapitału, pracy i ziemi) zgodnie z wolą przedsiębiorcy. To ugruntowane w kanonie nauk ekonomicznych i nauk o zarządzaniu podejście do produkcji stanowi podstawę sukcesu współczesnej gospodarki. W myśl ekonomii neoklasycznej integracja czynników produkcji pozwala na specjalizację, wywołanie zjawiska synergii, a w efekcie podniesienie wydajności i osiągnięcie rosnących efektów skali. Z kolei zgodnie z doktryną ekono-

1 O. Lange, Ekonomia polityczna, t. 1 i 2, Państwowe Wydawnictwo Naukowe, Warszawa 1978, s. 16-17, 295.

2 W. F. Samuelson, S. G. Marks, Ekonomia menedżerska, Polskie Wydawnictwo Ekonomiczne, Warszawa 1998, s. 229, 288.

${ }^{3}$ P. A. Samuelson, W. D. Nordhaus, Ekonomia, t. 1, PWN, Warszawa 2006, s. 188. 
mii instytucjonalnej, a konkretnie ekonomii kosztów transakcyjnych, granice przedsiębiorstw określa się przez porównanie kosztów wymiany rynkowej z kosztami zarządzania i administracji organizacji ${ }^{4}$. Odnosząc te rozważania do kwestii integracji i dezintegracji procesu produkcyjnego, można stwierdzić, że integracja ma na celu zwiększenie wydajności, natomiast jej optimum wyznacza wielkość kosztów wykorzystania mechanizmu cenowego ${ }^{5}$.

Istnieje jednak model produkcji, którego proces przyjmuje postać zdezintegrowaną $\mathrm{i}$ to $\mathrm{w}$ kategoriach globalnych. Zarówno $\mathrm{z}$ punktu widzenia przestrzennego jak i organizacyjnego, a nawet systemu zarządzania, proces wytwarzania odbywa się niezależnie dla każdego jego uczestnika. Chodzi tu o produkcję partnerską, którą Yochai Benkler (twórca tego pojęcia) definiuje, jako „...podzbiór działań produkcyjnych opartych na wspólnocie”. Wspólnota rozumiana jest tu jako zasoby, z których mogą indywidualne korzystać uczestnicy procesu mając do niej jednakowe prawa.

W procesie produkcji partnerskiej powstają produkty partnerskie, które są nieodpłatnie udostępniane wszystkim zainteresowanym. Tworzą one rodzaj wspólnoty (wspólnego zasobu), z której każdy może korzystać w sposób nieograniczony. Do najpopularniejszych produktów partnerskich należą: Apache HTTP Server, system operacyjny GNU/Linux, system zarządzania bazami danych MySQL i przeglądarka internetowa Firefox ${ }^{7}$ Również Wikipedia, Open Directory Project oraz różnorodne portale społecznościowe powstały dzięki zastosowaniu modelu produkcji partnerskiej. Ponieważ produkty partnerskie udostępniane są nieodpłatnie, na zasadach nietransakcyjnych, nie są czynnikiem generującym przychody. Dlatego za uczestnictwo w procesie produkcyjnym nie otrzymuje się wynagrodzenia. Skąd więc motywacja do tworzenia produktów o wysokiej wartości ekonomicznej, jeżeli wysiłek związany $\mathrm{z}$ ich wytwarzaniem nie jest rekompensowany ekwiwalentem pieniężnym? Pytanie to stanowi trzon podjętych w niniejszym artykule rozważań, których celem jest wyjaśnienie prawdopodobnych motywacji uczestników produkcji partnerskiej w kontekście dezintegracji samego procesu produkcyjnego. Jednocześnie postawiono tu dwie zasadnicze tezy. Pierwsza z nich stanowi, że motywacje uczestników produkcji partnerskiej są tożsame z motywacją do pracy zarobkowej, jednakże w przypadku modelu partnerskiego następu-

${ }^{4}$ Por. R. H. Coase, The Nature of the Firm, „Economica” 1937, 4(16), s. 386-405; O. E. Williamson, Ekonomiczne instytucje kapitalizmu, PWN, Warszawa 1998.

${ }^{5}$ R. H. Coase, op. cit., s. 390.

${ }^{6}$ Y. Benkler, Bogactwo sieci. Jak produkcja spoteczna zmienia rynki $i$ wolność, Wydawnictwa Akademickie i Profesjonalne, Warszawa 2008, s. 78.

7 Por. D. Tapscott, A. D. Williams, Wikinomia. O globalnej wspótpracy, która zmienia wszystko, Wydawnictwo Akademickie i Profesjonalne, Warszawa 2008, s. 43. 
je pominięcie medium pieniężnego. Druga teza odwołuje się do konieczności dezintegracji procesu produkcji partnerskiej, co prowadzi do obniżenia wysiłku koniecznego do podjęcia uczestnictwa w samym procesie.

\section{KONCEPCJA PRODUKCJI PARTNERSKIEJ}

Jeżeli produkcja to świadoma i celowa działalność ludzka, przystosowująca zasoby i siły przyrody, w celu wytworzenia dóbr ekonomicznych ${ }^{8}$, to $\mathrm{w}$ trakcie procesu produkcji przekształca się czynniki produkcji w półprodukty, a ostatecznie w produkty finalne ${ }^{9}$. W ujęciu ekonomii neoklasycznej proces produkcji przebiega w ramach przedsiębiorstw, które uznaje się za rodzaj „czarnej skrzynki”. Z jednej strony wprowadza się czynniki produkcji, natomiast z drugiej otrzymuje gotowe produkty ${ }^{10}$. Skrzynka stanowi parabolę zorganizowanego procesu produkcyjnego.

Modelem alternatywnym do neoklasycznego jest produkcja partnerska, której podstawy teoretyczne opisali Benkler ${ }^{11}$ oraz Benkler i Helen Nissenbaum $^{12}$. W tym przypadku proces produkcji przebiega $\mathrm{w}$ formie zdezintegrowanej, bez potrzeby tworzenia formalnej struktury przedsiębiorstwa. Nie występują tu żadne relacje hierarchiczne typu menedżer-pracownik, ani podwładności, na przykład pryncypał-agent ${ }^{13}$. Brak formalnego zarządzania, w ramach którego dzieli się kompetencje i rozdaje obowiązków.

Jak stwierdza Benkler produkcja partnerska toczy się wokół wspólnoty. Odróżnia ją to od produkcji tradycyjnie pojmowanej, która nierozerwalnie związana jest $\mathrm{z}$ własnością, określającą prawo do korzystania z procesu technologicznego ${ }^{14}$. Prawo własności daje konkretnym podmiotom możliwość osiągania korzyści materialnych. W modelu produkcji partnerskiej żaden z jej uczestników nie jest wyłącznym właścicielem ani technologii wytworzenia, ani samego produktu. W zasadzie każdy zainteresowany (nawet jeżeli nie tworzył produktu partnerskiego, a jedynie $z$ niego korzysta) ma do niego równe pra-

8 O. Lange, op. cit., s. 16-17, 295.

${ }^{9}$ W. F. Samuelson, S. G. Marks, op. cit., s. 288.

${ }^{10} \mathrm{~J}$. Lichtarski (red.), Podstawy nauki o przedsiębiorstwie, Wydawnictwo Akademii Ekonomicznej im. O. Langego we Wrocławiu, Wrocław 2001, s. 27.

${ }^{11}$ Y. Benkler, Coase's penguin, or Linux and the nature of the firm, "Yale Law Journal” 2002, 112(3), s. 369-446; Y. Benkler, Bogactwo sieci...

12 Y. Benkler, H. Nissenbaum, Commons-based Peer Production and Virtue, „The Journal of Political Philosophy”, 2006, 14 (4), s. 394-419.

13 Y. Benkler, Coase's penguin..., s. 381.

${ }^{14}$ Idem, Bogactwo sieci..., s. 76. 
wa. Stąd też nazwa „partnerska”15, która oznacza równości wszystkich podmiotów produkcji w kwestiach dysponowania produktem na każdym etapie jego wytwarzania.

Skupienie procesu produkcyjnego wokół wspólnoty czyni ją socjoekonomicznym systemem, który zrzesza duże grupy indywidualnych podmiotów (osób) ${ }^{16}$. Natomiast spaja je w całość współwłasność tworzonego produktu, która jednak nie daje prawa do bezpośredniego czerpania wymiernych korzyści finansowych. Oznacza to, że uczestnicy produkcji partnerskiej nie otrzymują za swoją pracę wynagrodzenia. Ich wkład w rozwijanie wspólnoty można porównać $\mathrm{z}$ wolontariatem, jednak specyficznym, gdyż nieumocowanym formalną umową współpracy.

W efekcie procesu produkcji partnerskiej, który jest charakterystyczny dla internetu ${ }^{17}$, powstają produkty partnerskie, które są nietransakcyjnymi produktami wirtualnymi. Wirtualność oznacza, że są to cyfrowe dobra informacyjne oraz kulturowe, które można przesłać (na przykład poprzez internet, ale również inne cyfrowe sieci komunikacyjne) szybko, bezbłędnie i tanio ${ }^{18}$. Do produktów wirtualnych, będących wytworami produkcji partnerskiej, należy zaliczyć przede wszystkim programy komputerowe, informacje (wiedza) oraz dobra kulturowe ${ }^{19}$. Nietransakcyjność przejawia się natomiast w nieodpłatnym udostępnianiu produktów partnerskich. Możliwe jest to ze względu na specyfikę kosztów krańcowych dóbr cyfrowych. Charakterystyka kosztów krańcowych produktów wirtualnych, odpowiada rozważanym przez Stana J. Liebowitza kosztom dóbr informacyjnych występujących w gospodarce rzeczywistej $^{20}$. Zgodnie z jego spostrzeżeniami, Yannis Bakos i Erika Brynjolfsson zaproponowali definicję dóbr informacyjnych, jako dóbr „o zerowych lub

15 Anglojęzyczne nazwa produkcji partnerskiej to peer production, gdzie peer należy rozumieć jako „osobę równej rangi”. Produkcję partnerską należałoby tłumaczyć dosłownie jako produkcję w ramach wspólnoty osób równych sobie (o tych samych uprawnieniach do dysponowania produktem).

${ }^{16}$ Y. Benkler, Nissenbaum H., op. cit., s. 394.

17 Por. ibidem.

18 Por. D. Begg, S. Fischer, R. Dornbusch, Mikroekonomia, Polskie Wydawnictwo Ekonomiczne, Warszawa 2007, s. 431; C. Shapiro, H. R. Varian, Potega informacji. Strategiczny przerwodnik po gospodarce sieciowej, Wydawnictwo HELION, Gliwice 2007, s. 15.

19 Y. Benkler, H. Nissenbaum, op. cit., s. 394.

${ }^{20}$ S. J. Liebowitz, Copying and Indirect Appropriabillity: Photocopying of Journals, „The Journals of Political Economy" 1985, nr 93(5), s. 945-957; por. także R. Dewan, M. Freimer, A. Seidmann, Organizing Distribution Channels for Information Goods on the Internet, "Management Science” 2000, nr 46(4), s. 483-495; Y. Bakos, E. Brynjolfsson, Bundling Information Goods: Pricing, Profits, and Efficiency, „Management Science” 1999, nr 45(12), s. 1613-1630; Y. Bakos, E. Brynjolfsson, Bundling and Competition on the Internet, „Marketing Science” 2000, nr 19(1), s. 63-82). 
bardzo niskich kosztach marginalnych produkcji” ${ }^{21}$. Przy czym określenie „zerowe" powinno być rozumiane jako tak niskie, że w praktyce nieistotne. Ponadto produkty wirtualne, w odróżnieniu od produktów fizycznych, nie są rzadkie. Wynika to $\mathrm{z}$ ich abstrakcyjnej formy, a konkretnie $\mathrm{z}$ faktu, że zbudowane są z bitów a nie atomów. Praktycznie każdy posiadający dostęp do internetu może za jego pośrednictwem pobierać udostępnione produkty wirtualne, ponosząc jedynie krańcowe koszty związane z czynnością kopiowania. Tego rodzaju konsumpcja nie wpływa na możliwości konsumpcyjne innych osób. Tworzona w ramach produkcji partnerskiej wspólnota nie będąc zbiorem atomów, nie maleje wraz z czerpaniem $z$ niej.

Filarami produkcji partnerskiej są dwie kardynalne zasady. Pierwsza głosi, że produkcja ma charakter zdecentralizowany. Oznacza to, że uczestnik procesu produkcyjnego podejmuje działania zgodnie $\mathrm{z}$ własną wolą i w wyznaczonym przez siebie zakresie. Osoba podejmująca wysiłek uczestnictwa w procesie produkcji partnerskiej kieruje się „okazjami”, które sama dostrzega. Okazję można utożsamiać $\mathrm{z}$ możliwością stworzenia nowego produktu partnerskiego, na który istnieje potencjalne zapotrzebowanie, modyfikacją czy też udoskonaleniem już istniejącego lub jedynie ze skopiowaniem ${ }^{22}$. Podjęcie trudu uczestnictwa $\mathrm{w}$ procesie produkcji jest całkowicie dobrowolne - niepodyktowane odgórnym poleceniem menedżera, przełożonego czy biurokraty.

Druga zasada produkcji partnerskiej polega na tym, że kierunek działań wynika z sygnałów i motywacji społecznej. Mechanizm koordynacji oparty na czynnikach społecznych zastępuje grę rynkową oraz polecenia zwierzchników struktur formalnych ${ }^{23}$.

Aby proces produkcji partnerskiej mógł przebiegać, wymagane jest spełnienie trzech warunków. Pierwszy związany jest z koniecznością dzielenia procesu na moduły (komponenty). Wymagane jest to ze względu na możliwość niezależnego opracowywania poszczególnych elementów składających się na gotowy produkt partnerski. Drugi warunek to optymalny rozmiar modułu podlegającego procesowi produkcji. Benkler i Nissenbaum warunek ten określają mianem szczegółowości (granularity). Dobranie jej właściwego poziomu pozwala na skupienie dużej liczby uczestników, o relatywnie niskim stopniu motywacji do działania. Ostatnim warunkiem jest niski koszt integracji modułów, który często przebiega automatycznie ${ }^{24}$. Spełnienie wyżej wymienionych

21 Y. Bakos, E. Brynjolfsson, Bundling Information..., s. 1616; Y. Bakos, E. Brynjolfsson, Bundling and Competition..., s. 64.

${ }^{22}$ Kopiowanie produktu wirtualnego oznacza jego reprodukcję, czyli stworzenie kolejnego egzemplarza. Odnosząc to działanie do produkcji rzeczywistej należy je uznać za produkcję.

${ }^{23}$ Y. Benkler, H. Nissenbaum, op. cit., s. 400.

${ }^{24}$ Ibidem, s. 400-401. 
warunków pozwala na zachowanie zasady decentralizacji, i w praktyce oznacza dezintegrację procesu produkcji.

\section{MOTYWACJE UCZESTNIKÓW PRODUKCJI PARTNERSKIEJ A DEZINTEGRACJA PROCESU PRODUKCJI}

Motywacja jest siłą napędową skłaniającą ludzi do realizacji konkretnych celów. Według Abrahama H. Maslowa, człowiek motywowany jest koniecznością zaspokojenia kombinacji potrzeb ${ }^{25}$. W tym celu podejmuje zdywersyfikowane działania, które w zależności od kontekstu kulturowego i posiadanych zasobów, mogą przyjmować różnorodną postać. Niezależnie od swojej formy prowadzą one do tego samego celu, czyli ostatecznie likwidacji poczucia niespełnienia, wynikającego $\mathrm{z}$ braku.

Zgodnie z koncepcją Aleksandra Kamińskiego, który swoje rozważania opiera na teorii motywacji Maslowa, można wyróżnić dwie grupy potrzeb. Potrzeby $z$ niedostatku oraz potrzeby rozwoju. Pierwsza grupa obejmuje potrzeby fizjologiczne, bezpieczeństwa, afiliacji i szacunku. W drugiej grupie znajdują się potrzeby związane $\mathrm{z}$ samorealizacją (samourzeczywistnianiem się). Kamiński potrzeby z niedostatku uznaje za pierwotne, czyli charakterystyczne dla każdego człowieka. Natomiast potrzeby rozwoju traktuje jako indywidualne, związane ściśle $\mathrm{z}$ konkretną osobą. Mogą się one wyrażać w potrzebie twórczości, posiadania wiedzy i kontemplacji piękna ${ }^{26}$. Zaspokajanie potrzeb $\mathrm{z}$ niedostatku zapobiega powstawaniu chorób mentalnych - na przykład nerwicom, nie gwarantuje jednak osiągnięcia zdrowia psychicznego. $Z$ kolei realizacja potrzeb rozwoju zapewnia jednostce zdrowie psychiczne oraz pełne zadowolenie z życia. Reasumując, według Kamińskiego działania człowieka motywowane są celem nadrzędnym, czyli osiągnięciem zdrowia psychicznego.

Podejmowanie działań o charakterze gospodarczym, w tym pracy produkcyjnej, wynika więc z naturalnego dążenia do zdrowia psychicznego. Dążenie to nie jest jednak bezpośrednie. Stanowi jedynie element procesu zaspakajania potrzeb. W zależności od konkretnej sytuacji na pierwszy plan mogą wychodzić potrzeby, których nienasycenie skłania człowieka do przeznaczania swoich zasobów na cele cząstkowe. W kontekście podejmowania pracy zarobkowej motywacja bezpośrednia wynika $z$ chęci osiągnięcia dochodów. Jednak odwo-

25 A. H. Maslow, Motywacja i osobowośc, Instytut Wydawniczy Pax, Warszawa 1990, s. $59-60$.

${ }^{26}$ A. Kamiński, Funkcje pedagogiki spotecznej. Praca socjalna i kulturowa, PWN, Warszawa 1982, s. 48-49; zob. także A. H. Maslow, Motywacja..., s. 114. 
łując się do rozważań Williama S. Jevonsa ${ }^{27}$, który za główną przesłankę towarzyszącą podaży pracy uznawał satysfakcję, można wysnuć wniosek, że praca jest jedynie półśrodkiem do realizacji potrzeb, które można zaspokoić poprzez zakup dóbr ekonomicznych. Przy czym nie można pominąć faktu, że praca sama w sobie również może być źródłem zaspokojenia niektórych potrzeb, na przykład afiliacji lub szacunku. Nie ulega jednak wątpliwości, że część potrzeb, chociażby fizjologicznych lub bezpieczeństwa (nie tylko rozumianego jako atawistyczne poszukiwanie schronienia, ale również w kontekście finansowym) musi być zaspokojona w trakcie konsumpcji odpłatnych dóbr ekonomicznych. W takim kontekście praca zarobkowa jest jedynie źródłem zasobów (wyrażonych w medium pieniężnym), służących realizacji kolejnych celów pośrednich, ostatecznie zmierzających do zaspokojenia potrzeb z niedostatku i rozwoju.

Przekładając powyższe rozważania na płaszczyznę produkcji partnerskiej można stwierdzić, że zasadniczo jej uczestnicy kierują się tą samą siłą, czyli koniecznością zaspokojenia potrzeb. Różnica polega na pominięciu medium pieniężnego, czyli skróceniu łańcucha realizacji potrzeb. Łączy się to również z niwelacją kosztów transakcyjnych, gdyż nie zachodzi wymiana w sensie ekonomicznym odbywająca się w warunkach rynkowych, której owe koszty towarzyszą. Dotyczy to zarówno kwestii zatrudnienia pracowników procesu produkcyjnego, jak również obrotu samymi produktami. Fakt ten sprzyja rozwojowi produkcji partnerskiej, ponieważ jak udowadnia Kenneth J. Arrow koszty transakcyjne to „...koszty funkcjonowania systemu gospodarczego [które, gdy są zbyt wysokie - przyp. S.C.] generalnie hamują, a w szczególnych przypadkach całkowicie blokują, formowanie się rynków"28. W kontekście produkcji partnerskiej niwelacja kosztów transakcyjnych związanych $\mathrm{z}$ wymianą rynkową stanowi o przewadze tej formy produkcji nad modelem neoklasycznym - aczkolwiek nie w każdej sytuacji.

Posługując się nomenklaturą Maslowa, wśród wyróżnionych przez niego pięciu typów potrzeb, za pośrednictwem produkcji partnerskiej można realizować potrzebę przynależności, szacunku i samorealizacji ${ }^{29}$. Przy czym, stopień realizacji tych potrzeb może być jedynie cząstkowy. Dlatego nadużyciem byłoby stwierdzić, że produkcja partnerska może stanowić doskonały substytut pracy zarobkowej lub stosunków społecznych występujących poza internetem. Natomiast uprawniona jest teza, że produkcja partnerska stanowi kom-

${ }_{27}$ W. S. Jevons, The Theory of Political Economy, MacMillan and Co., London-New York 1888, s. 167-169; por. M. Blaug, Teoria ekonomii. Ujęcie retrospektywne, PWN, Warszawa 2000, s. 318.

${ }_{28}$ O. E. Williamson, op. cit., s. 32-33.

29 A. H. Maslow, A Theory of Human Motivation, „Psychological Review” 1943, 50, s. 370396; A. H. Maslow, Motywacja..., s. 72-86. 
plementarną formę działań ludzkich prowadzących do zachowania zdrowia psychicznego.

Działania o tym charakterze nie byłby niczym nowym, gdyż wpisują się w zakres teorii wymiany społecznej, gdyby nie fakt, że w ich efekcie powstają pełnowartościowe dobra, które mogą z kolei zaspakajać potrzeby innego rodzaju osób, niezwiązanych $\mathrm{z}$ uczestnictwem w procesie produkcji partnerskiej. Tak więc, na zasadzie kosztu alternatywnego, uczestnicy produkcji partnerskiej rezygnują $\mathrm{z}$ wynagrodzenia $\mathrm{w}$ celu bezpośredniej realizacji wybranych potrzeb.

Hierarchia potrzeb opracowana przez Maslowa w swoim założeniu jest uniwersalna, dlatego też należy ją interpretować jako całe grupy potrzeb, które mogą się składać z różnych potrzeb cząstkowych. W zależności od kontekstu kulturowego oraz poziomu rozwoju cywilizacyjnego (również technologicznego), koszyk potrzeb cząstkowych będzie różny. Dzięki internetowi możliwe było rozwinięcie na szeroką skalę kultury ekspozycjii ${ }^{30}$, w ramach której ukształtowały się postawy wymagające realizacji konkretnych potrzeb. Produkcja partnerska daje możliwość realizacji potrzeby ekspozycji, ekspresji, samoprezentacji lub bardziej kolokwialnie, zaistnienia w świecie masowej popkultury. Przykładem tej tendencji jest silny rozwój portali społecznościowych, takich jak Facebook lub nasza-klasa. Właściciele tego rodzaju portali wykorzystują produkcję partnerską do tworzenia wartości swoich produktów. Sam program obsługujący treści na portalu nie miałby żadnej wartości (również $\mathrm{w}$ sensie ekonomicznym) bez informacji zamieszczanych przez poszczególnych użytkowników. Wykonywana przez nich praca, ma charakter partnerski, gdyż skupiona jest wokół wspólnoty, a tworzony w jej ramach produkt jest nietransakcyjny.

Motywem podejmowania produkcji partnerskiej, o charakterze ekonomicznym, jest oczekiwanie na późniejsze wymierne korzyści majątkowe jakie można uzyskać uczestnicząc nieodpłatnie w procesie produkcyjnym. Jeżeli przyjąć, że uczestnictwo w produkcji partnerskiej łączy się z kosztem alternatywnym produkcji zarobkowej, to osoba podejmująca się go może liczyć na zwrot, nazwijmy to, inwestycji w późniejszym terminie. Motywy tego rodzaju można porównać z budowaniem własnego kapitału ludzkiego. Okres uczestnictwa w procesie produkcji partnerskiej związany jest $\mathrm{z}$ nauką i tworzeniem własnej reputacji, na przykład zawodowej. Taki schemat działania spotykany jest często u programistów związanych z produktami partnerskim takimi jak programy komputerowe.

${ }^{30}$ C. Anderson, Dtugi ogon. Ekonomia przysztości - każdy konsument ma gtos, Media Rodzina, Poznań 2008, s. 110-111; zob. rów. T. Wu, Leggo My Ego. Google Print and the other culture war, Slate 2005, dostęp 07.10.2011 z lokalizacji: http://www.slate.com/articles/news_and_politics/jurisprudence/2005/10/leggo_my_ego.html. 
Produkcja partnerska dostarcza programistom niezbędnego doświadczenia zawodowego oraz pozwala na zaistnienie na rynku pracy. Szczególnie popularna jest wśród studentów, którzy rozpoczynają pracę zawodową posiadając, dzięki takim działaniom, pewien dorobek. Najbardziej jaskrawym przykładem jest tu współtwórca systemu operacyjnego GNU/Linux Linus Torvalds. Jego wkład w tworzenie produktu partnerskiego pozwolił mu na osiągnięcie sukcesu zawodowego jako programiście oraz propagatorowi koncepcji otwartego zródta, czy formą tworzenia oprogramowania zgodnego z modelem produkcji partnerskiej ${ }^{31}$.

Przedstawione wyżej motywy produkcji partnerskiej w zależności od indywidulanych predyspozycji uczestników mogą być silniejsze bądź słabsze. Liczba osób o relatywnie dużym potencjale motywacyjnym jest oczywiście niewielka. Zdecydowana większość będzie charakteryzowała się relatywnie niskim stopniem motywacji podjęcia wysiłku produkcyjnego. Stąd konieczność dezintegracji samego procesu. Jedynie w formie zdezintegrowanej proces uzyska wystarczającą liczbę uczestników, która gwarantuje powstanie produktu partnerskiego. Jeżeli encyklopedia internetowa Wikipedia nie byłaby przystosowana do indywidualnej edycji poszczególnych haseł, trud jej stworzenia byłby zbyt duży, aby mógł się tego ktoś podjąć, bez odpowiedniej rekompensaty finansowej.

Ponadto dezintegracja zapewnia również różnorodność, czyli indywidualne podejście do przedmiotowych kwestii. Czynnik ten stanowi o wysokiej innowacyjności produktów partnerskich, których rozwój ma cechy ewolucyjne. Różnorodność i modułowość procesu produkcji pozwala na poszukiwanie różnych dróg rozwoju produktu. Cecha ta jest właściwa dla oprogramowania komputerowego. Rozwijanie jednocześnie i niezależnie przez indywidulane osoby konkretnych wersji oprogramowania skutkuje pojawieniem się więcej niż jednej ścieżki rozwoju. Optymalne udoskonalenie danej wersji może okazać się mniej wartościowe niż niedopracowanie nowej wersji. Kevin Kelly uwidocznił tego rodzaju tendencje jako różne ścieżki prowadzące do osiągniecia szczytowych możliwości w sieciowym uniwersum indywiduów ${ }^{32}$. Dezintegracja sprawia, że radykalne zmiany przebiegają swobodnie. Uczestnicy produkcji partnerskiej nie identyfikują się bezpośrednio z wcześniej opracowanymi wersjami, gdyż zwykle są one kompilacją pracy innych uczestników. Pozwala to na złagodzenie bariery przyzwyczajenia do zastosowanych już rozwiązań i sprzyja twórczej destrukcji.

${ }^{31}$ D. Tapscott, A. D. Williams, Wikinomia. O globalnej wspótpracy, która zmienia wszystko, Wydawnictwa Akademickie i Profesjonalne, Warszawa 2008, s. 110.

32 K. Kelly, Nowe reguty nowej gospodarki. Dziesięć przetomowych strategii dla świata potaczonego siecia, Wig-Press, Warszawa 2001, s. 73-84. 
Zgodnie ze statystykami Linux Foundation jądro Linuxa (wersja 2.6.35) liczy około 13,5 mln linii, a w jego produkcji (od wersji 2.6.11) uczestniczyło 6,1 tys. osób ${ }^{33}$. W samej wersji 2.6 .35 uczestniczyło 1,2 tys. osób, co oznacza wyraźną rotację uczestników procesu produkcji. Nowi uczestnicy mają ambiwalentny stosunek do wykonanej już pracy, poddając ją nieskrępowanej krytyce. Ponadto jedna trzecia uczestników wykonuje dokładnie jedną modyfikację. Co oznacza, że wysiłek indywidualny związany z pracą przy produkcie końcowym jest nieznaczny.

\section{ZAKOŃCZENIE}

Reasumując podjęte $\mathrm{w}$ niniejszym artykule rozważania, można stwierdzić, że motywy uczestnictwa w procesie produkcji partnerskiej można analizować w trzech kategoriach: psychologicznej, społecznej i ekonomicznej, przy czym każda z tych płaszczyzn zachodzi na siebie tworząc rodzaj interdyscyplinarnej platformy. W ujęciu psychologicznym nadrzędnym motywem jest naturalne dla człowieka dążenie do osiągnięcia zdrowia psychicznego, chyli de facto wewnętrzny przymus do „wspinania” się na coraz wyższe poziomy hierarchii potrzeb. Przy czym działaniom wywołanym tego rodzaju motywacjami towarzyszy formowanie się społecznego systemu sygnałów i bodźców, zastępującego formalne struktury organizacyjne. Ponadto w wymiarze gospodarczym następuje eliminacja medium pieniężnego, a dokładniej wyparcie jego funkcji cyrkulacyjnej przez bezpośrednią realizacje potrzeb $\mathrm{w}$ toku uczestnictwa $\mathrm{w}$ procesie produkcji. Wyparcie struktur formalnych oraz medium pieniężnego związane jest z niwelacją kosztów transakcyjnych oraz kosztów administracji organizacji - mamy tu do czynienia z oszczędnością zasobów w kontekście ekonomicznym. Brak kosztów transakcyjnych, wynikający z nietransakcyjnego charakteru produktów partnerskich oraz braku płac uczestników go wytwarzających (zatrudnienie pracowników również należy traktować jako transakcję), sprzyja nieskrępowanemu jej rozwojowi.

W ujęciu społecznym motywatorem produkcji partnerskiej jest odzwierciedlenie podjętych działań w kontekście zaistnienia w globalnej grupie społecznej, jaką tworzą internauci. Forma ta przy relatywnie niskich nakładach pozwala uczestnikom produkcji partnerskiej dać wyraz własnej indywidualności w masowej kulturze. Taka forma ekspresji własnych zainteresowań na dużym forum publicznym sprzyja kojarzeniu się grup o podobnych preferencjach.

33 J. Corbet, G. Kroah-Hartman, A. McPherson, Linux Kernel Dervelopment. How Fast it is Going, Who is Doing It, What They are Doing, and Who is Sponsoring It, The Linux Foundation, 2010, s. 8-10. 
W aspekcie czysto ekonomicznym, motywatorem uczestnictwa w produkcji partnerskiej jest osiąnniecie odroczonej korzyści. Podobnie jak w opisywanych już wyżej przypadkach - korzyści te uzyskiwane są dzięki platformie społecznej jaką tworzy internet. Żadne przywołane tu motywy działania nie mają jednolitego źródła, a na ich podejmowanie wpływa splot czynników szczegółowych. To co sprzyja podejmowaniu trudu produkcji partnerskiej to fakt, że nawet niski poziom motywacji może być bodźcem prowadzącym do jego podjęcia. Dogodność ta wynika bezpośrednio z dezintegracji procesu produkcyjnego na drobne wycinki (moduły).

\section{BIBLIOGRAFIA}

Anderson C., Dtugi ogon. Ekonomia przysztości - każdy konsument ma gtos, Media Rodzina, Poznań 2008.

Bakos Y., Brynjolfsson E., Bundling and Competition on the Internet, „Marketing Science" 2000, nr 19(1), s. 63-82.

Bakos Y., Brynjolfsson E., Bundling Information Goods: Pricing, Profits, and Efficiency, „Management Science” 1999, nr 45(12), s. 1613-1630.

Begg D., Fischer S., Dornbusch R., Mikroekonomia, Polskie Wydawnictwo Ekonomiczne, Warszawa 2007.

Benkler Y., Bogactwo sieci. Jak produkcja spoteczna zmienia rynki $i$ wolność, Wydawnictwa Akademickie i Profesjonalne, Warszawa 2008.

Benkler Y., Coase's penguin, or Linux and the nature of the firm, "Yale Law Journal” 2002, nr 112(3), s. 369-446.

Benkler Y., Nissenbaum H., Commons-based Peer Production and Virtue, „The Journal of Political Philosophy" 2006, nr 14(4), s. 394-419.

Blaug M., Teoria ekonomii. Ujęcie retrospektywne, PWN, Warszawa 2000.

Castells M., Wiek informacji: ekonomia, spoteczeństwo i kultura (t. 1: Spoteczeństwo sieci), PWN, Warszawa 2007.

Coase R.H., The Nature of the Firm, „Economica” 1937, nr 4(16), s. 386-405.

Corbet J., Kroah-Hartman G., McPherson A., Linux Kernel Development. How Fast it is Going, Who is Doing It, What They are Doing, and Who is Sponsoring It, The Linux Foundation, 2010.

Dewan R., Freimer M., Seidmann A., Organizing Distribution Channels for Information Goods on the Internet, „Management Science” 2000, nr 46(4), s. 483-495. Jevons W. S., The Theory of Political Economy, MacMillan and Co., London-New York 1888. Kamiński A., Funkcje pedagogiki spotecznej. Praca socjalna i kulturowa, PWN, Warszawa 1982 ,

Kelly K., Nowe reguty nowej gospodarki. Dziesięć przetomowych strategii dla swiata potaczonego siecia, Wig-Press, Warszawa 2001.

Lange O., Ekonomia polityczna, t. 1 i 2, PWN, Warszawa 1978. 
Lichtarski J. (red.), Podstawy nauki o przedsiębiorstwie, Wydawnictwo Akademii Ekonomicznej im. O. Langego we Wrocławiu, Wrocław 2001.

Liebowitz S. J., Copying and Indirect Appropriabillity: Photocopying of Journals, „The Journals of Political Economy" 1985, nr 93(5), s. 945-957.

Maslow A. H., A Theory of Human Motivation, „Psychological Review” 1943, nr 50, s. 370-396.

Maslow A. H., Motywacja i osobowość, Instytut Wydawniczy Pax, Warszawa 1990.

Samuelson P. A., Nordhaus W. D., Ekonomia, t. 1, PWN, Warszawa 2006.

Samuelson W. F., Marks S. G., Ekonomia menedżerska, Polskie Wydawnictwo Ekonomiczne, Warszawa 1998.

Shapiro C., Varian H. R., Potega informacji. Strategiczny przewodnik po gospodarce sieciowej, Wydawnictwo HELION, Gliwice 2007.

Tapscott D., Williams A. D., Wikinomia. O globalnej wspótpracy, która zmienia wszystko, Wydawnictwo Akademickie i Profesjonalne, Warszawa 2008.

Williamson O. E., Ekonomiczne instytucje kapitalizmu, PWN, Warszawa 1998.

Wu T., Leggo My Ego. Google Print and the other culture war, Slate 2005, dostęp 07.10.2011 z lokalizacji: http://www.slate.com/articles/news_and_politics/jurisprudence/2005/10/leggo_my_ego.html.

\section{PRODUKCJA PARTNERSKA W INTERNECIE JAKO PRZYKŁAD GLOBALNEJ DEZINTEGRACJI PROCESU PRODUKCJ}

\section{STRESZCZENIE}

Niniejszy artykuł jest próbą wyjaśnienia przyczyn podejmowania produkcji partnerskiej w kontekście decentralizacji procesu produkcji. W artykule postawiono dwie zasadnicze tezy. Pierwsza stanowi, że motywacje uczestników produkcji partnerskiej są tożsame z motywacją do pracy zarobkowej. Aczkolwiek w przypadku modelu partnerskiego następuje pominięcie medium pieniężnego, gdyż uczestnicy nie otrzymują wynagrodzenia za wykonany produkt. Druga teza wskazuje na potrzebę dezintegracji procesu produkcji partnerskiej, co pozwala na obniżenie wysiłku koniecznego do poniesienia przez każdego uczestnika. W artykule przedstawiono koncepcję produkcji partnerskiej, jako procesu zdezintegrowanego, oraz zestawiono ją z modelami motywacji prowadzącymi do jej podjęcia. Wywód poparto przykładami najpopularniejszych produktów partnerskich, takich jak program operacyjny GNU/Linux czy encyklopedia internetowa Wikipedia.

\section{PEER PRODUCTION ON THE INTERNET AS AN EXAMPLE OF GLOBAL DISINTEGRATION OF PRODUCTION PROCESS}

\section{SUMMARY}

The article is an attempt to explain the reason for participation in peer production in the context of decentralization of production process. There are two main 
theses. The first is that the motivations of participants in production are the same as motivation for gainful employment. Although in the case of the partnership production model bypasses the medium of money, because the participants do not receive payment for manufactured products. The second argument indicates the need for the disintegration of peer production process, because it's reducing effort required to be borne by each participant. The article presents the concept of peer production, as disintegrated process, and compares it with models of motivation leading to its take. The argument supports the most popular examples of peer products such as software GNU/Linux and Internet encyclopaedia Wikipedia. 
